\title{
Shape Controllability for Quarter Buckles of Strip in 20-high Sendzimir Mills
}

\author{
Kenji HARA, Toshiro YAMADA and Kazuhiro TAKAGI ${ }^{1)}$
}

Surface Treatment Department, Steel R \& D Laboratories, Nisshin Steel Co., Ltd., Ishizu-nishi-machi, Sakai, Osaka-fu, 592 Japan.

1) Steel R \& D Laboratories, Nisshin Steel Co., Ltd., Showa-cho, Kure, Hiroshima-ken, 737 Japan.

(Received on September 17, 1990; accepted in final form on December 14, 1990)

\begin{abstract}
A simulation model for predicting the shapes of cold-rolled strips in 20-high Sendzimir mills was developed, and its predicting accuracy was assessed experimentally. By this model, improvement of quarter buckles was shown difficult merely by conventional shape control actuators, i.e., lateral shifts and taper profiles of first intermediate rolls, roll crowns of work rolls and second intermediate rolls, and crown adjustment of back-up rolls. It was shown that quarter buckles could be effectively corrected by giving a concave profile partially to the first intermediate rolls.
\end{abstract}

KEY WORDS: 20-high Sendzimir mill; numerical analysis; strip rolling; strip shape; first intermediate roll.

\section{Introduction}

In cold rolling for hard materials such as stainless steel sheets, for which surface luster is very important, 20-high Sendzimir mills are used widely. However, when comparing 20-high Sendzimir mills to 4-high mills and 6-high mills, the work rolls of the former have smaller diameters so that elastic deformation of the work rolls becomes complicated and rolled strips tend to have complex and inferior shapes. 20high Sendzimir mills have actuators for controlling the strip shape, i.e., lateral shifts and taper profiles of first intermediate rolls, crown of the work roll and AS-U crown adjustment. However, these actuators could not easily correct complex and inferior shapes, thus making imperative the development of a new shape control method.

The authors studied the elastic deformation of rolls for 20-high Sendzimir mills and developed a simulation model for strip shape." In this paper the effects of actuators for controlling complex and inferior shapes accompanying quarter buckles are examined by this simulation model.
Furthermore, a new rolling method by rolls having partially concave profiles is proposed for improving quarter buckles, and shape controllability by the method was verified experimentally using an actual mill.

\section{Simulation Model for Strip Shape}

\subsection{Assumptions for Calculations}

The main assumptions in this simulation model are as follows:

(1) As shown in Fig.1, each roll of a 20-high Sendzimir mill is arranged symmetrically about the $Y$-axis on an $X-Y$ plane and point symmetrically around the origin on this plane. Elastic deformation of the rolls and plastic deformation of a sheet are thus assumed to meet the said symmetrical conditions, and 6 rolls marked by hatching are considered objects for calculation.

(2) In calculating the deflection of rolls, back-up rolls are assumed to be solid. However, for calculation of the distribution of contact pressures $q^{4}, q^{5}, q^{6}$ between the back-up

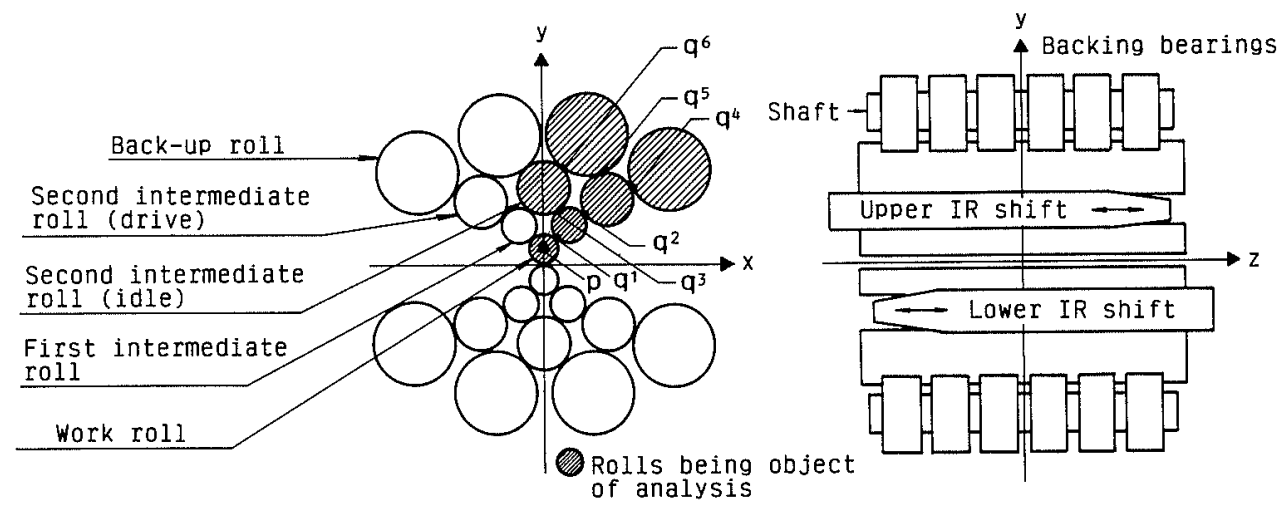

(a) Side view

(b) Front view

Fig. 1. Schematic arrangement of rolls in a 20-high Sendzimir mill. 
and second intermediate rolls, the buck-up rolls are considered to have bearing construction. ${ }^{2}$ )

(3) There is no lateral spread in the strip.

(4) The effect of thermal crown of the work roll is not considered.

\subsection{Outline of Mathematical Models}

Figure 2 shows the calculation procedure for the present model. Equations required for analysis of strip shape are outlined hereinafter.

\subsubsection{Calculation of Roll Deflection}

The deflection of rolls can be calculated from rolling force $P$ acting on a work roll and the distribution of contact pressure $q^{m}$ between rolls.

Here, calculations of deflection of rolls were made by the slit model of Shohet et al. . $^{3)}$ However, in the present model, ${ }^{1)}$ load distribution within each slit element was calculated as

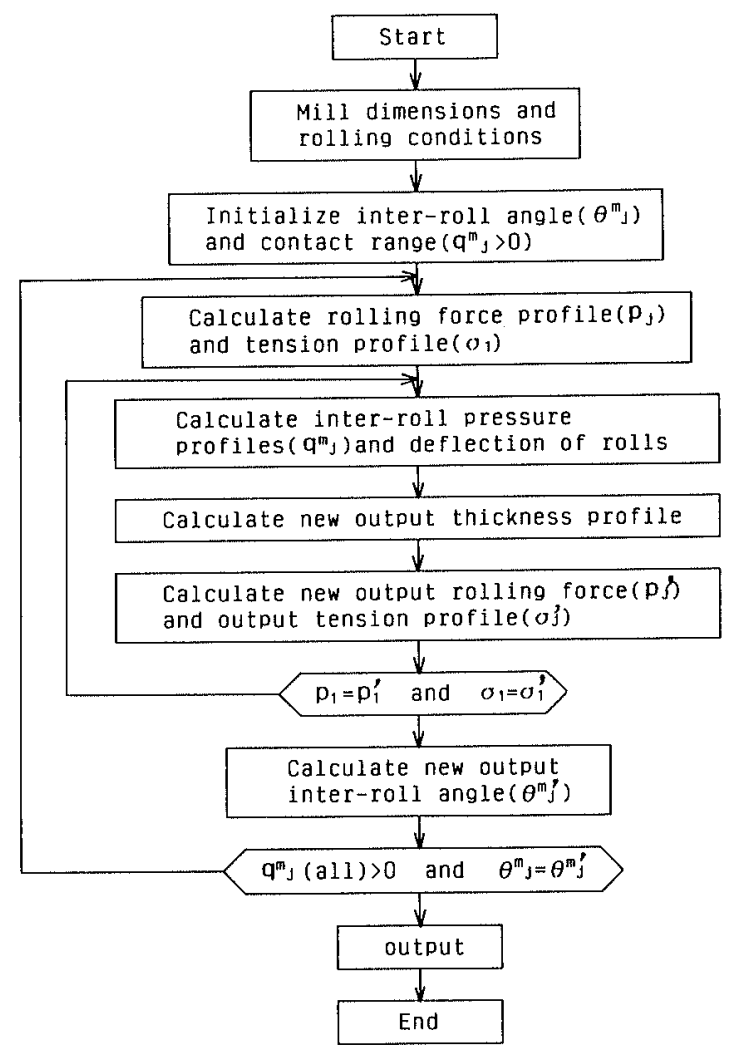

Fig. 2. Calculation procedure of the model.

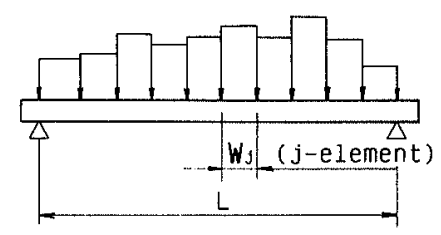

(a) Uniformly distributed load in each element

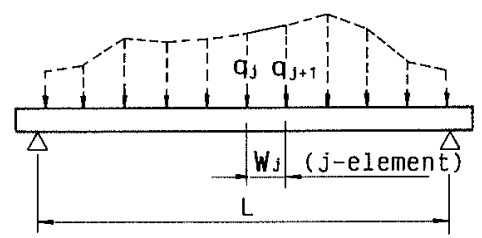

(b) Linearly distributed load in each element

Fig. 3. Load distribution. a linearly distributed load as shown in Fig.3 instead of a uniformly distributed load. ${ }^{4,5}$

This can be expressed by formulas (1) and (2) for comparison.

Uniformly distributed loads:

$$
\delta i=\sum_{j=1}^{n} \delta_{i j}=\sum_{j=1}^{n} K_{i j} q_{j} W_{j}
$$

Linearly distributed loads:

$$
\delta i=\sum_{j=1}^{n} \delta_{i j}=\sum_{j=1}^{n}\left(K_{i j}^{1} q_{j} W_{j}+K_{i j}^{2} q_{j+1} W_{j}\right) \ldots \ldots
$$

where, $n$ is the number of slits, $\delta$ the deflection of roll for $i$-th slit and $K_{i j}$ the influence coefficient by a load of $j$-th slit on the roll deflection of the $i$-th slit.

The deflection of a work roll in Fig.4 means the difference in the sum of upper and the lower work roll displacement between the mid-span $(\mathrm{Z}=0 \mathrm{~mm})$ of the roll and edge position $(Z=600 \mathrm{~mm})$. When calculating by the uniformly distributed load model, a large number of elements are required to obtain values of sufficient accuracy. The linearly distributed load model method depends to a far less degree on the number of elements; for example, should facilities for computation be restricted, the linearly distributed load model will be superior to the uniformly distributed load model in accuracy. The present analysis method thus gives highprecision calculating results using a smaller number of elements.

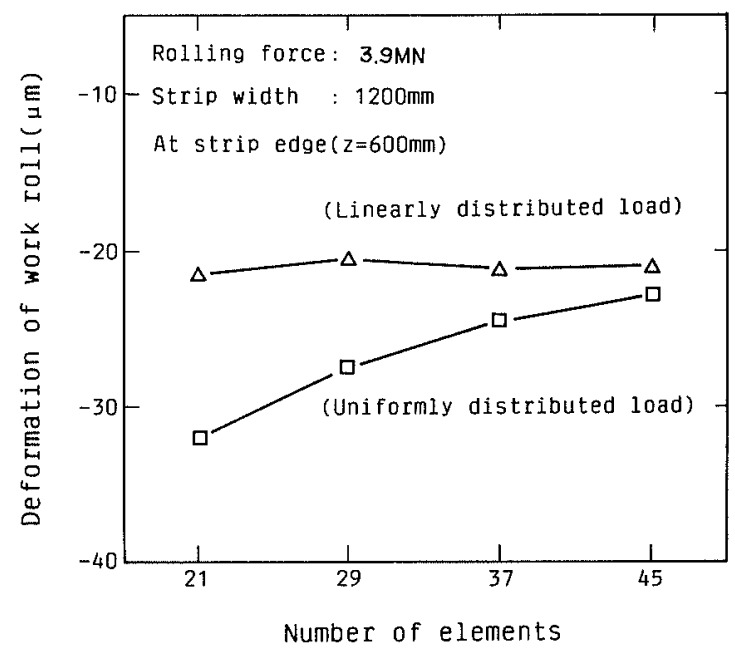

Fig. 4. Relation between work roll deflection and number of portions.

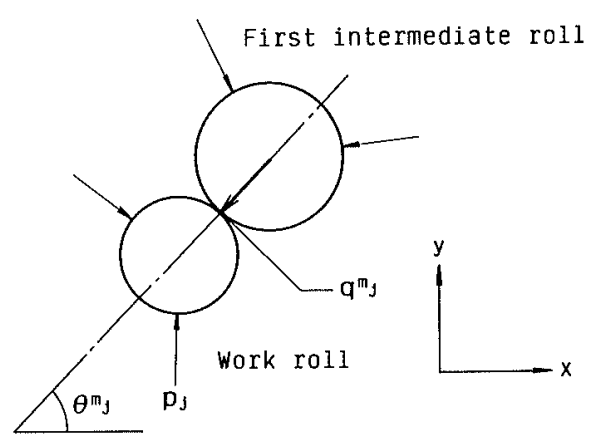

Fig. 5. Loads acting on work roll and first intermediate roll. 


\subsubsection{Pressure between Rolls and Equilibrium Conditions}

Figure 5 shows a combination of loads acting between a work roll and a first intermediate roll as an example of loads acting on rolls. Plural distributed loads $P_{j}, q^{m}{ }_{j}$ act in certain directions on each roll. These loads and moments satisfy the equilibrium conditions. According to Eq.(2), the deflection of rolls is calculated from the distributed loads and moments. The distributed load $q_{j}^{m}$ is calculated with mutual flattening of a pair of mating rolls using the spring model. . $^{\text {) }}$

Based on the above, when the transverse distribution of a rolling load $P_{j}$ is given, equations of roll displacement and those of the distribution of contact load are evaluated by numerical compatibility, and the solution to elastic deformation of a roll is obtained based on equilibrium conditions. ${ }^{4,5)}$

\subsubsection{Calculation of Rolling Force Distribution}

The distribution of a rolling force $P_{j}$ was solved by simultaneous equations of Hill's formula ${ }^{7)}$ for rolling force function and Hitchcock's equation for flattening of a work roll surface in contact with a rolled strip.

\subsubsection{Calculation of the Thickness Profile of a Rolled Strip and Tension Distribution}

The thickness profile of a rolled strip was determined by connecting the deflection of a work roll due to $P_{j}$ and $q^{m}{ }_{j}$

Table 1. Roll dimension.

\begin{tabular}{|c|c|c|}
\hline \multicolumn{2}{|c|}{ Diameter of work rolls } & $50 \mathrm{~mm}$ \\
\hline \multicolumn{2}{|c|}{ Diameter of first intermediate rolls } & $102 \mathrm{~mm}$ \\
\hline \multicolumn{2}{|c|}{ Diameter of second intermediate rolls (drive) } & $173 \mathrm{~mm}$ \\
\hline \multicolumn{2}{|c|}{ Diameter of second intermediate rolls(idle) } & $173 \mathrm{~mm}$ \\
\hline \multicolumn{2}{|c|}{ Diameter of backing bearings } & $300 \mathrm{~mm}$ \\
\hline \multicolumn{3}{|c|}{ Taper of first intermediate roll } \\
\hline & Taper angle & Taper length \\
\hline First taper $T_{l}$ & $20 / 10000$ & $275 \mathrm{~mm}$ \\
\hline Second taper $T_{2}$ & $10 / 10000$ & $150 \mathrm{~mm}$ \\
\hline Third taper $T_{3}$ & $1.5 / 10000$ & $150 \mathrm{~mm}$ \\
\hline
\end{tabular}

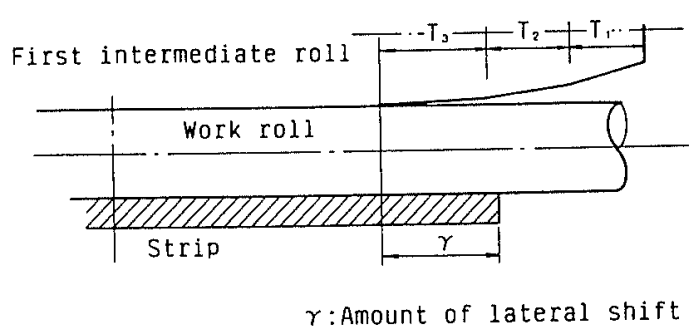

Table 2. Rolling conditions.

\begin{tabular}{ll}
\hline Material & SUS430 \\
\hline Inlet thickness: $H(\mathrm{~mm})$ & 0.25 \\
Outlet thickness: $h(\mathrm{~mm})$ & 0.20 \\
Strip width: $B(\mathrm{~mm})$ & 680 \\
Rolling speed: $V(\mathrm{~m} / \mathrm{min})$ & 50 \\
Front tension: $: T_{f}\left(\mathrm{~N} / \mathrm{mm}^{2}\right)$ & 330 \\
Back tension: $: T_{b}\left(\mathrm{~N} / \mathrm{mm}^{2}\right)$ & 210 \\
Roll crown $: C R(\mu \mathrm{m})$ & 0 \\
\hline
\end{tabular}

with the distribution of flattening of a work roll surface. ${ }^{8)}$ The deformation of a rolled strip was calculated by the slit model which considers the feedback of forward tension.

\subsection{Accuracy of Model}

The predicting accuracy of the present model was confirmed by an actual 20-high Sedzimir mill 1ZM at Shunan Works of Nisshin Steel. The roll dimensions of 1ZM and rolling conditions are shown in Tables 1 and 2, respectively. Experiments were conducted by changing only the positions of the first intermediate rolls $\gamma$ with other rolling conditions kept constant. In this case, $\gamma$ is defined as the distance between edge areas of strip and the taper starting point of a roll. The steepness of a sheet after rolling was measured at 15 positions in the lateral direction of the strip. The effect of $\gamma$ on strip shape was compared for calculated and measured values, as shown in Fig.6. The distribution of steepness was expressed for one side only after averaging the values for symmetrical positions about the center of the width. Both calculated and measured results indicated complex shapes mixed together with center or quarter buckles and edge waves. The calculated values agreed fairly well with those measured except for the edge areas of the strip, thereby substantiating the effectiveness of predicting strip shape from 20-high Sendzimir mills by the present model. Also, the reason for non-coincidence in shapes at edge areas may have been influenced by thermal crown and lateral spread in the strip, which were not taken into account in this model.

\section{Influence of Conventional Shape Control Actuators on Strip Shape}

By the present simulation model, the effects of conventional control actuators on strip shape in 20-high Sendzimir mills were examined.

\subsection{Effect of First Intermediate Roll Position}

Figure 6 shows examples of experiments and calculations that indicate the influence of the position of the first intermediate roll $\gamma$ on strip shape. Strip shape was affected considerably by $\gamma$. Although the shape of quarter buckles decreased as $\gamma$ shifted toward the center of the strip width, complex and inferior shapes with severer center buckles were produced. Quarter buckles increased when $\gamma$ shifted to the edge side of a strip. It is thus evident that obtaining flat

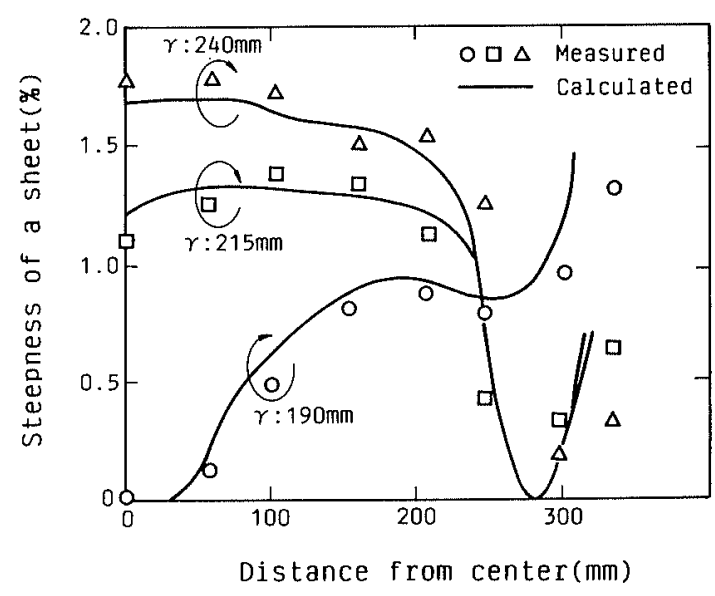

Fig. 6. Comparison of measured and calculated shape profiles of a rolled strip. 
shape having no quarter buckles by only controlling of $\gamma$ is difficult.

\subsection{Effect of Taper Profile of First Intermediate Roll}

So that the taper profile of first intermediate rolls would correspond as much as possible to the complicated deflection of work rolls expressed by a higher order function, threestage straight-line tapers were combined and the effects of respective taper angles on the strip shape were determined. The taper conditions of first intermediate rolls are shown in Table 1.

Figure 7 shows a case in which respective taper angles have changed while maintaining $\gamma$ constant. Each taper angle must have a valid geometrical relation such that $T_{1}>T_{2}$ $>T_{3}$. As indicated by the calculations results, the influence of each taper angle on the strip shape is great.

With decrease in the first taper angle $T_{l}$ or the third taper angle $T_{3}$, or increase in the second taper angle $T_{2}$, the strip assumed a complex and inferior shape with larger quarter

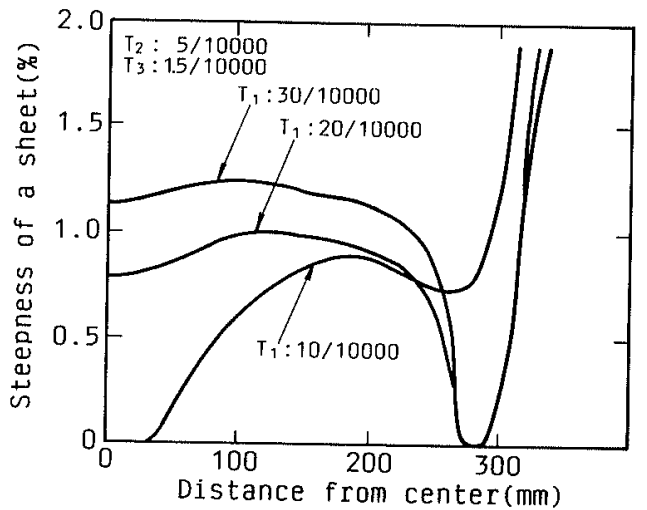

(a) $T_{1}$

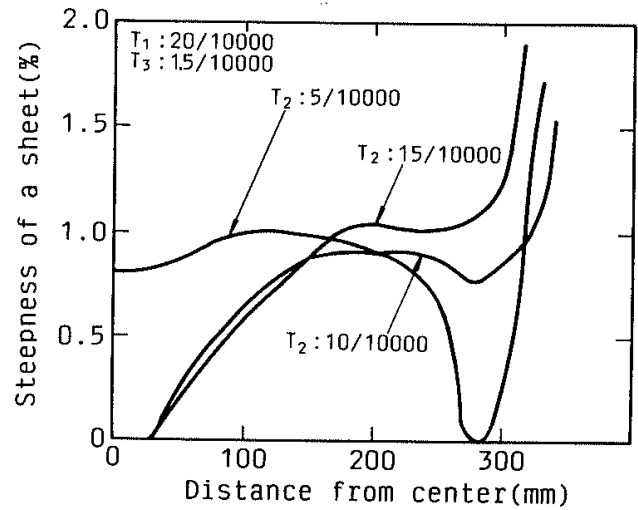

(b) $T_{2}$

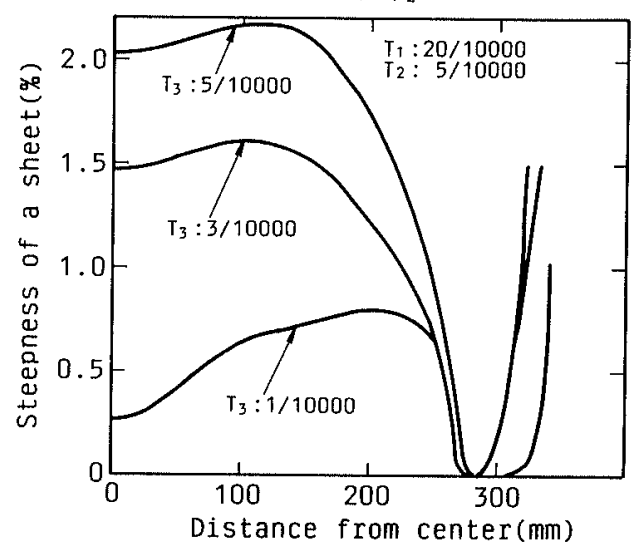

(c) $\mathrm{T}_{3}$

Fig. 7. Effects of first intermediate roll profiles on strip shape. buckles being produced. When $T_{1}$ or $T_{3}$ were made larger, or $T_{2}$ made smaller, the strip took on a complex and inferior shape with severer center buckles.

Even a combination of three-stage tapers cannot failed to give a taper profile corresponding to the complicated deflection of a work roll. To prevent quarter buckles, the taper profile should apparently have a high order function. However, such a function cannot be easily derived theoretically.

It was thus concluded that the taper profile of first intermediate rolls alone cannot give a flat shape having no quarter buckles.

\subsection{Effect of Initial Roll Crown}

Figure 8 shows examples of the effects of the work roll crown $\mathrm{CR}$ on strip shape. Changes in $\mathrm{CR}$ ranging from 0 to $10 \mu \mathrm{m}$ obviously caused little change in strip shape. The quarter buckles are generally expressed as a profile by a higher order function. However, the work roll crown $C R$ is normally given by a profile closely resembling a parabola and thus by itself cannot improve the shape of quarter buckles.

This is also true when a roll crown is given to second intermediate rolls.

\subsection{Effect of AS-U Roll Crown Adjustment}

Back-up rolls of 20 -high Sendzimir mills are divided into several backing bearings in the axial direction. The extent of push-in of each backing bearing is arbitrarily adjusted by saddles, and mechanism for which is designated as AS-U roll crown adjustment. Calculation was subsequently made for strip shape by the present model under a condition such that the extent of push-in of backing bearing at quarter portions changed from minimum to maximum. The results are shown in Fig.9 from which it is quite evident that strip shape with severe quarter buckles hardly improves even though the degree of AS-U roll crown adjustment changed to a maximum. AS-U roll crown adjustment may possibly improve effectively simple shape defects such as edge waves. However, in this study, AS-U roll crown adjustment failed to have any effect for preventing quarter buckles.

Rolling pressure distribution may thus possibly cause little local change in quarter portions by AS-U roll crown adjustment alone.

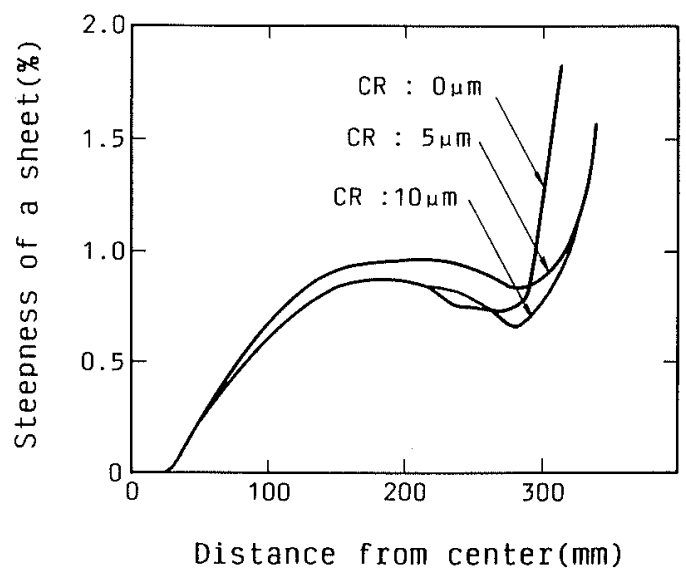

Fig. 8. Effect of work roll crown on strip shape. 


\section{Rolling Characteristics by Concave Rolls}

The flat shape of a rolled strip having no quarter buckles cannot be obtained merely by conventional functions for shape control. Rolling by concave rolls having a concave profile in the longitudinal section of roll, was thus developed as a local shape control method. Shape controllability for quarter buckles by rolling with concave rolls was analyzed by the present model, and the effects of concave rolls on correction of the quarter buckles were clarified experimentally using an actual mill 1ZM.

\subsection{Selection of Rolls with Concave Profile}

Figure 10 indicates schematically the means for obtaining concave profiles for work rolls, the first and second intermediate rolls. In the case of work rolls and second intermediate rolls having flat profiles, it was assumed that two concave positions with depth $\mathrm{C}$ and width $\mathrm{W}$ should be

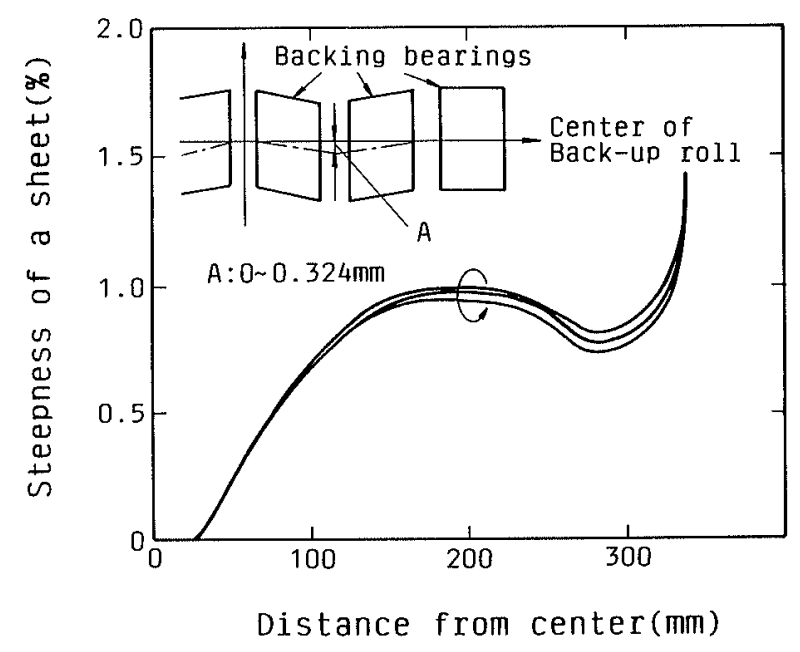

Fig. 9. Effect of push-in of backing bearings (AS-U crown control) on strip shape.

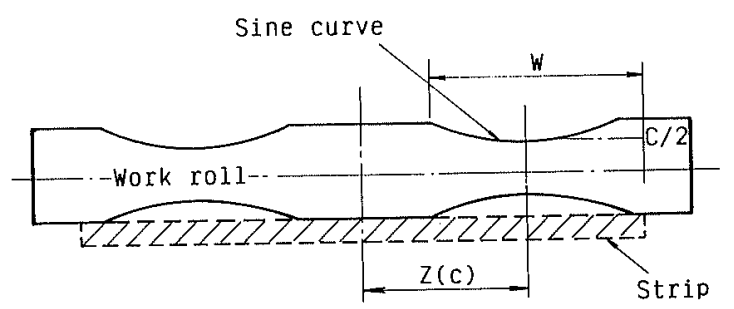

(a) Work roll and second intermediate roll

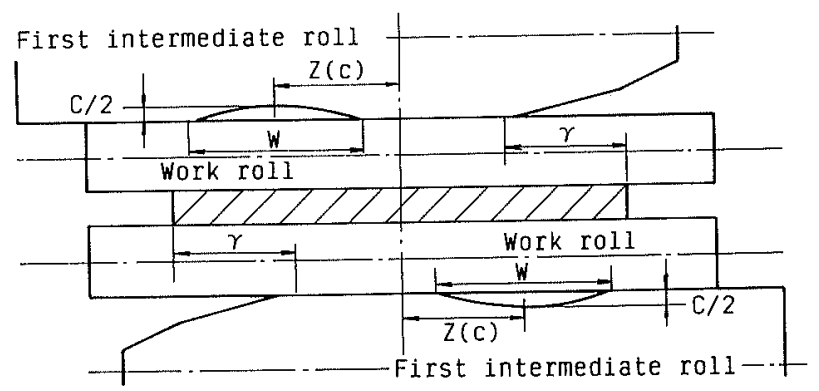

(b) First intermediate roll symmetrical at the positions of rolls corresponding to quarter positions of the rolled strips shown in Fig.10(a). In the case of first intermediate rolls having a taper at one side, calculation was made assuming a concave positions only at the flat side opposite the taper side, as shown in Fig.10(b).

Figure 11 shows calculation results for relations between concave depth $C$ and steepness difference $\Lambda 4$, where $\Lambda 4$ was defined as the difference in steepness between the center and quarter positions of strip width. In all cases, $\Lambda 4$ decreased with $C$, and there was a certain value of $C$ at which $\Lambda 4$ zero was in each case. However, if $\mathrm{C}$ exceeded a certain value, $\Lambda 4$ changed from zero to a negative value, indicating the shape of the rolled strip to change from quarter to center buckles. Thus, when controlling shape by concave rolls, the value of $\mathrm{C}$ which makes steepness zero should be predicted accurately.

As indicated by the calculation results, the effect of $\mathrm{C}$ on strip shape was greatest in the case of work rolls. If a proper concave profile, which makes $\Lambda 4$ zero, can be given to work rolls, improvement in quarter buckles should be maximal. However, the optimum value of $\mathrm{C}$ that made quarter buckles zero was only $4 \mu \mathrm{m}$. Thus, when applying a concave profile to work rolls, shape control depends on the accuracy of roll grinding, thereby easily resulting in unstable rolling which is a shortcoming.

Secondly, when giving a concave profile to second intermediate rolls, the $C$ required is extremely large and concave profiles must be given to 6 rolls.

Finally, when applying a concave profile to first intermediate rolls, the $\mathrm{C}$ required to make quarter buckles zero is considerably larger than in the case of work rolls, and the effect of roll grinding accuracy may be considerably reduced. The greatest effect for preventing quarter buckles is thus concluded to be application of a concave profile to first intermediate rolls.

\subsection{Optimization of Concave Profile}

Figure 12 shows the effects of concave width W on strip shape, where concave profiles were made for first intermediate rolls, concave depth $\mathrm{C}$ was given as $8 \mu \mathrm{m}$, and $\mathrm{W}$, as 100,200 and $300 \mathrm{~mm}$. Steepness at quarter portion decreased when using the concave roll. However, the overall shape of the strip changed in a complicated manner with decreased in concave width $\mathrm{W}$, possibly due to differences in rolling pressure distribution.

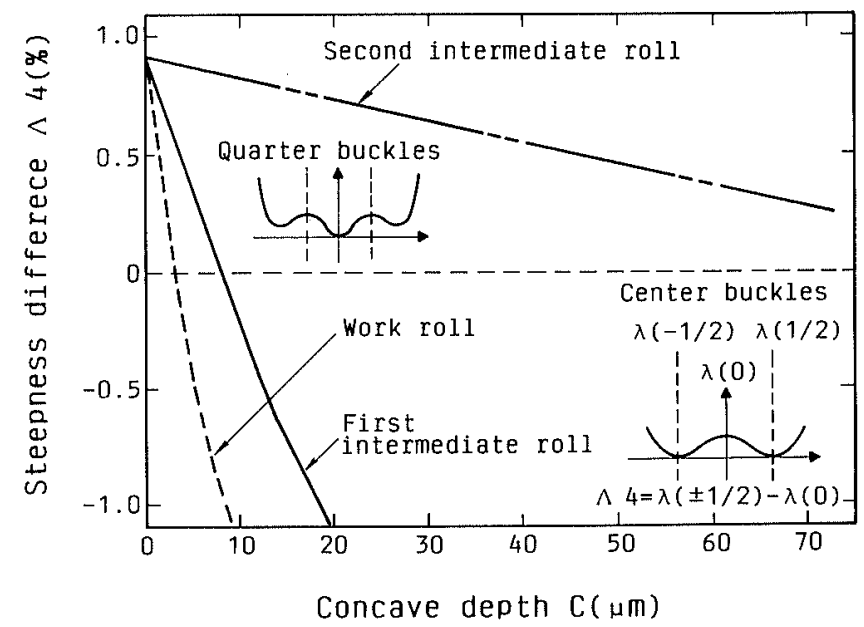

Fig. 11. Effects of concave depth on quarter buckles.

Fig. 10. Structure of concave roll. 
Figure 13 shows the effect of concave width $\mathrm{W}$ on the distribution of contact pressure $q^{\prime}$ between a work roll and a first intermediate roll. Contact pressure $q^{l}$ was found to vary with $\mathrm{W}$, and have the smoothest profile about quarter positions opposite the taper side when $\mathrm{W}=300 \mathrm{~mm}$, this being nearly equal to one-half the strip width. When concave width $\mathrm{W}$ was more than one-half the strip width, the concave portions of the upper and the lower first intermediate rolls overlapped to lessen the effect of a concave profiled roll for preventing quarter buckles. The optimum concave width should thus be one-half the strip width.

Examples of the distribution of contact pressure $q^{m}$ and rolling pressure $P$ are shown in Fig.14, where $\mathrm{C}$ is $8 \mu \mathrm{m}$ and $\mathrm{W}, 300 \mathrm{~mm}$ as the optimum concave profile for the first intermediate rolls.

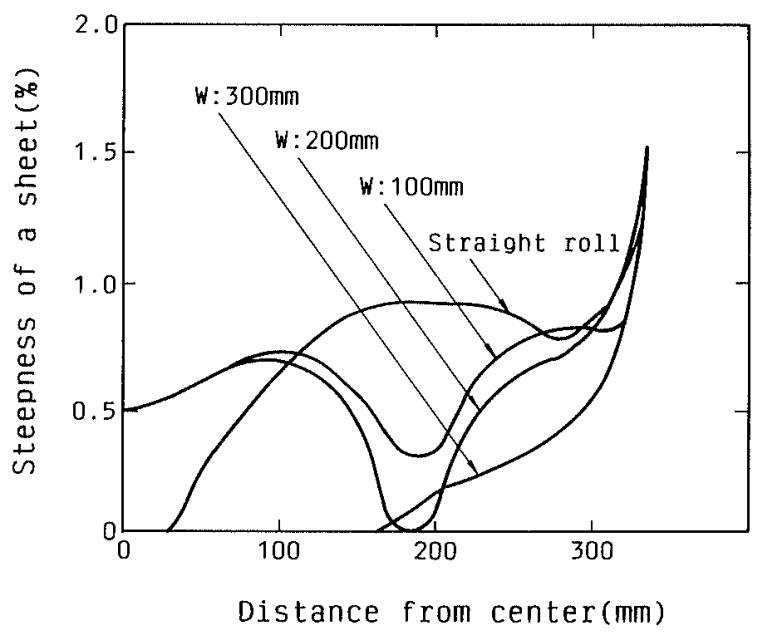

Fig. 12. Effect of concave width on strip shape.

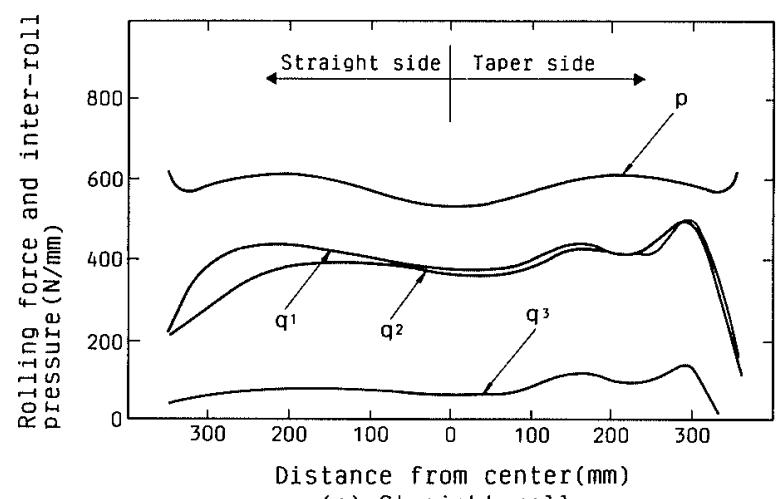

(a) Straight roll

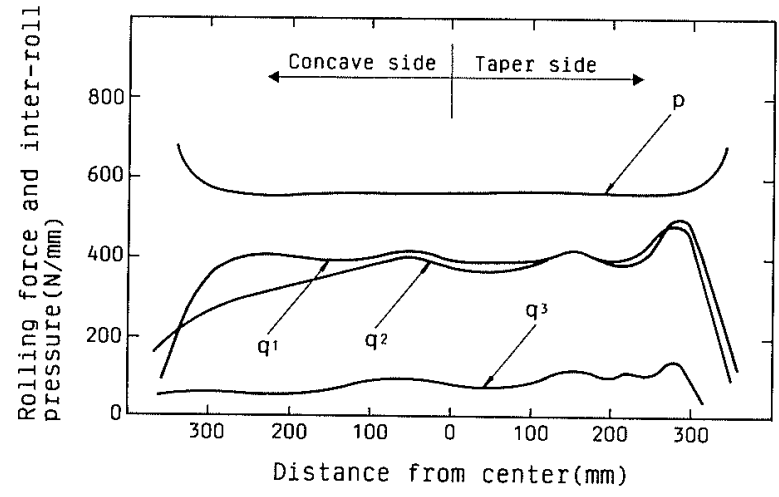

(b) Concave roll

Fig. 13. Effect of concave width $\mathrm{W}$ on the distribution of contact pressure $q^{\prime}$.
Rolling pressure $P$ and contact pressure $q^{\prime}$ between the work roll and first intermediate roll were maximum at quarter portions in the case of a straight roll, whereas $P$ and $q$ showed flatter curves in the case of the optimum concave profiled roll. Contact pressures $q^{2}, q^{3}$ between the first intermediate and second intermediate rolls were also reduced at quarter portions by giving a concave profile to the first intermediate roll. It thus follows the concave roll has the effect of leveling rolling pressure.

\subsection{Rolling Tests Using an Actual Mill}

The effect of a concave roll for preventing quarter buckles was verified by cold rolling of ferritic stainless steel SUS 430 with an actual 20-high Sendzimir mill 1ZM at Shunan Works of Nisshin Steel. The roll dimensions of $1 \mathrm{ZM}$ and rolling conditions are shown in Tables 1 and 2, respectively. The optimum concave profile for making quarter buckles zero was given to the first intermediate rolls at quarter positions to the opposite side of the taper, where concave depth $\mathrm{C}$ was $8 \mu \mathrm{m}$ and concave width $\mathrm{W}, 300 \mathrm{~mm}$.

Figure 15 shows a comparison of calculated and measured distributions of steepness of a rolled strip after one-pass rolling depending on the presence of concaves. When rolling was conducted with rolls having no concaves, typical quarter buckles were observed at both quarter positions of a rolled strip with a steepness of about $0.8 \%$. Quarter buckles were not observed in the case of concave rolls and the steepness of quarter positions of the strip was reduced to less than $0.3 \%$. In both the above cases, the calculated results were in good agreement with the measured values.

Although a flat shape was obtained as essentially predicted, edge waves at the edge areas of the strip were observed. However, these waves occurred even by rolling without concave rolls, and thus, appears not characteristic of

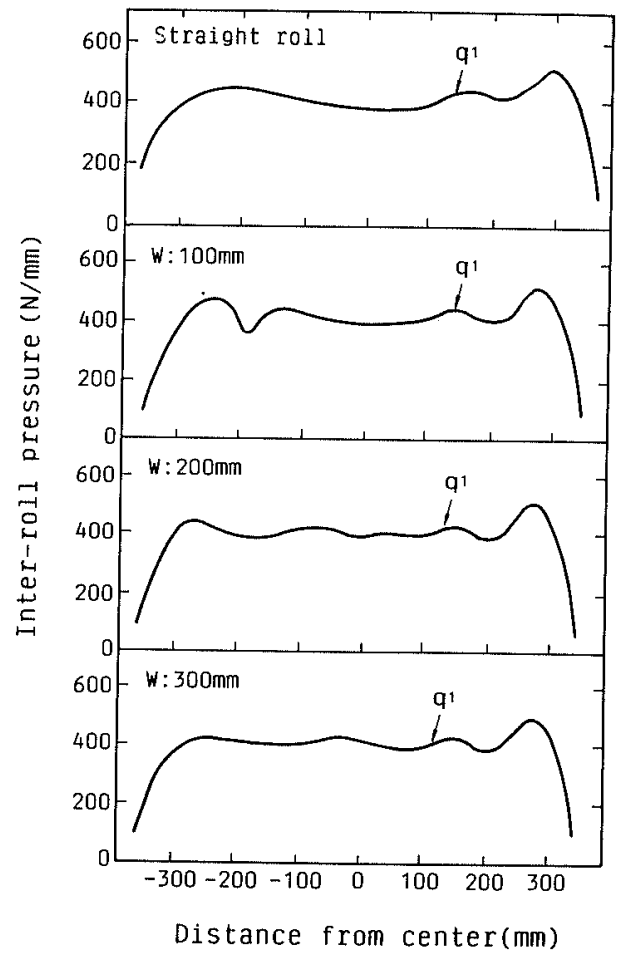

Fig. 14. Distribution of rolling force and contact pressure in rolling. 


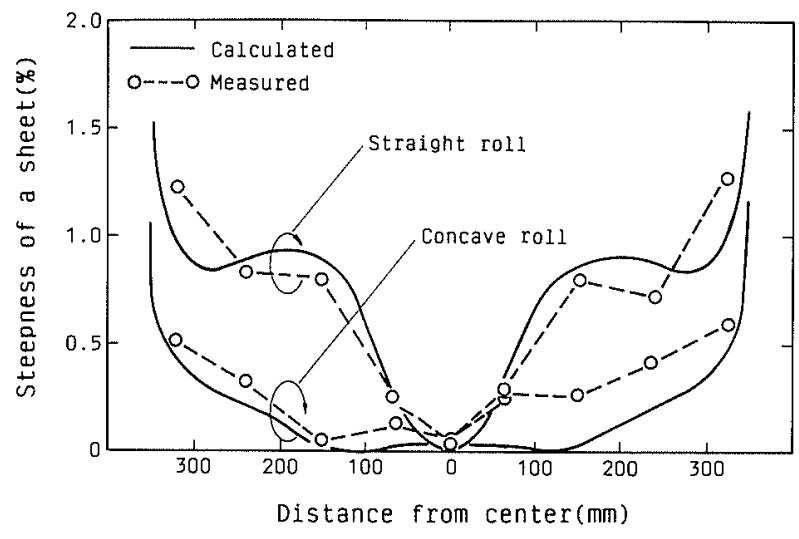

Fig. 15. Effect of concave roll on quarter buckles.

rolling by concave rolls. Since these edge waves are a simple defects in shape, correction should be easy to conduct by proper AS-U roll crown adjustment.

The present results clearly show that quarter buckles can be improved and flat shape of a rolled strip can be obtained through application of concave rolls to first intermediate rolls in 20-high Sendzimir mills.

\section{Conclusions}

A simulation model for predicting strip shape in 20-high Sendzimir mills was developed, and a method for preventing quarter buckles, problematic for hard materials such as stainless steel, was devised.

(1) A high accuracy prediction method by the present model was verified experimentally using an actual 20-high Sendzimir mill. The model was found to predict exactly the occurrence of quarter buckles in a rolled strip.

(2) Calculation results showed it to be difficult to prevent quarter buckles by common actuators for strip shape control such as lateral shifts and the taper profiles of first intermediate rolls, the crown of work rolls and AS-U crown of buck-up rolls.

(3) It was clarified analytically and experimentally that quarter buckles could be effectively prevented by giving a concave profile to first intermediate rolls. The optimum profile of the concave roll was determined.

\section{REFERENCES}

1) T. Matsuda, S. Matsubara, K. Hara, A. Takezoe, E. Kawano and T. Shirai: Nisshin Steel Tech. Rep., 57(1987), 22.

2) A. Mizuta, S. Hattori and Y. Yamaguchi: J. Jpn. Soc. Technol. Plast., 28(1987), 1042.

3) K. N. Shohet and N. A. Townsend: J. Iron Steel Inst., 206(1968), 159.

4) A. Mizuta, S. Hattori, Y. Yamaguchi and K. Tsuzi: J. Jpn. Soc. Technol. Plast., 23(1982), 1245.

5) T. Kono, M. Ogaya, T. Matsushita, N. Yoneyama and Y. Aizawa: Nippon Stainless Tech. Rep., 17(1982), 95.

6) M. D. Stone and R. Gray: Iron Steel Eng., (1965), No.8, 73.

7) R. Hill: The Mathematical Theory of Plasticity, Oxford Univ. Press, Oxford, (1950).

8) Y. Tozawa and M. Ueda: J. Jpn. Soc. Technol. Plast., 11(1970), 29. 